\title{
Atlantis
}

Critical Studies in Gender, Culture \& Social Justice

Études critiques sur le genre, la culture, et la justice

\section{Speaking Freely and Freedom of Speech: Feminists Navigating the "New" Right}

\section{Rachel Alpha Johnston Hurst and Jennifer L. Johnson}

Volume 41, Number 1, 2020

URI: https://id.erudit.org/iderudit/1074011ar

DOI: https://doi.org/10.7202/1074011ar

See table of contents

Publisher(s)

Mount Saint Vincent University

ISSN

1715-0698 (digital)

Explore this journal

Cite this document

Hurst, R. \& Johnson, J. (2020). Speaking Freely and Freedom of Speech:

Feminists Navigating the "New" Right. Atlantis, 41(1), 1-8.

https://doi.org/10.7202/1074011ar

All Rights Reserved (C) Rachel Alpha Johnston Hurst, Jennifer L. Johnson, 2020

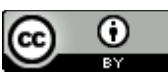

This document is protected by copyright law. Use of the services of Erudit (including reproduction) is subject to its terms and conditions, which can be viewed online.

https://apropos.erudit.org/en/users/policy-on-use/ 


\section{"Speaking Freely and Freedom of Speech: Feminists Navigating the 'New' Right"}

Rachel Alpha Johnston Hurst is Associate Professor of Women's and Gender Studies at St. Francis Xavier University in Antigonish, Nova Scotia. She is author of Surface Imaginations: Cosmetic Surgery, Photography, and Skin (2015) and co-editor of Skin, Culture, and Psychoanalysis (2013). Her most recent essays have been published in History of Photography, Feminist Studies, Configurations, and Body \& Society.

Jennifer L. Johnson is Associate Professor of Women's, Gender, and Sexuality Studies, Thorneloe University at Laurentian. She is co-editor of Feminist Issues: Gender, Race, and Class 6th edition (Pearson Education 2016), Feminist Praxis Revisited: Critical Reflections on University-Community Engagement (WLUP 2019) and Maternal Geographies: Mothering In and Out of Place (Demeter Press 2019).
$A^{t}$ the end of October 2018, posters appeared on OK to be White." The message bore similarity to previous messaging and graffiti left on university campuses stating "White Lives Matter" as direct backlash to the Black Lives Matter movement in 2016 and 2017. The 'alt-right,' 'alternative right,' or 'new right' as it has come to be known, is a largely online ideology that unifies a variety of smaller movements opposed to mainstream conservatism and roughly attempts to consolidate values and ideas that seem to them to be lost under an evermore liberal society (Hodge and Hallgrimsdottir 2020). As many students of feminist thought will contend, even as voices of the so-called altright spill out onto university campuses, the content of their ideas are not new. Feminist thinkers will add these public expressions of white racial anxiety to feminist analyses of those documented during the abolition and civil rights eras, and the aftermath of $9 / 11$, among other examples. In conjunction with white nationalist statements, some of these messages have also included anti-Semitic, anti-immigrant, anti-feminist, and anti2SLGBTQ+ language, and in some cases mention direct links to white nationalist organizations. Thankfully, such affirmations of white supremacy and misogyny stand in contrast to the vocal documentation and protest of a range of injustices in Canada (and the United States) today.

These injustices include the loss of life, physical injury, and psychic violence caused by police brutality against Black and Indigenous people, as well as very public attacks led by white men against racialized people and Indigenous women (Gillis 2020, Globe 2020, Ibrahim 2020 , Porter 2017). The past decade has also seen brutal attacks on large groups of people or individual women by men who identify as incels, whose social media activities often reveal links between misogyny, xenophobia, and racism and identify women, immigrants, and Black, Indigenous, and people of colour as the 
source of their aggrievement (Boisvert 2020, CBC News 2020a and 2020b, Pickard 2020). The restrictions placed on the arrivals of refugees by the Canadian state, and particularly refugees who are people of colour, may well galvanize a new generation of human rights activism on a global scale (Humphreys 2020). The totality of these hostile messages aimed at 'others' signals the need for attention to systemic and everyday gendered, racialized, and sexualized violence in Canadian society. The dismantling of normative investments in white supremacy in North America is slow and by no means a given.

A common thread that connects these acts of violence is the idea that Canadian institutions-including universities - have become places that actively exclude and silence "white men," to use Sara Ahmed's shorthand (2014), and that violent retribution is justified as a response. With varying levels of visibility and commitment to change, many Canadian universities recognize the importance of acknowledging and making amends for historical and contemporary harm wrought by their racist practices as part of the Canadian state-at least in universities' supportive public statements and public relations. Institutions like universities may have acknowledged racialized violence through special lectures, teach-ins, and vigils, as many did after Barbara Kentner was fatally struck in Thunder Bay, Ontario, on January 29, 2017 (a crime for which the charges were downgraded from murder to manslaughter in 2020). Public commitments to combating racism —and especially anti-Black racism-by universities most recently proliferated after the mass public demonstrations of protest in North America in response to the murder of George Floyd by police in Minneapolis, Minnesota on May 25, 2020, and Breonna Taylor in Louisville, Kentucky on June 13, 2020, and in Canada, the violent deaths of Regis Korchinski-Paquette in Toronto, Ontario on May 27, 2020 and Chantel Moore in Edmundston, New Brunswick on June 4, 2020.

However, these public declarations of opposition to racism and expressed commitment to developing better internal procedures and policies could be considered a part of what a diversity practitioner interviewed by Sara Ahmed for On Being Included: Racism and Institu- tional Life aptly characterizes as "doing the document rather than doing the doing” $(2012,86)$. Public statements and policy-making risk becoming practices that stifle dissent and critique (especially internally) while presenting an inclusive anti-racist public face that does not represent the reality for those studying and working in those spaces. As Frances Henry, Enakshi Dua, Carl E. James, Audrey Kobayashi, Peter Li, Howard Ramos, and Malinda S. Smith and many others have documented, Indigenous and racialized faculty are underrepresented across the ranks of these institutions, and face overt racism and microaggressions at work. Their work is undervalued in tenure and promotion processes; at the same time, the internal procedures and policies to address racism at work are inadequate and often fail (Henry et al. 2017, 297-8). Like university faculty, racialized and Indigenous students face conditions similar to those described by Black at Western, a group of alumni who graduated over decades from Western University. They record traumatic exposure to racist professors and an unsympathetic university administration (Rodriguez 2020). Black at Western refer specifically to the white supremacist psychologist J. Philippe Rushton and also to white professors who insist on speaking the n-word aloud in class. Eternity Martis's memoir They Said This Would Be Fun: Race, Campus Life, and Growing Up (2020) extends this picture through narrating her experience as a Black woman and undergraduate student at Western, where she faced racist verbal harassment, assault, and physical threats, as well as constant microaggressions, from other students and community members. ${ }^{1}$

The tension between the public face of the university and the silenced experiences of oppression within creates impossible conditions for racialized and Indigenous faculty, students, and staff, and may compound the negative experiences of those who are queer, trans, feminist, and disabled. Institutional accountability is often circumvented through a public condemnation or statement of solidarity. Further, Ameil J. Joseph, Julia Janes, Harjeet Badwall and Shana Almeida astutely critique how these statements frequently expose racialized members of university communities to further harassment and threats, and that such statements are also often made alongside a proclamation of the value of free speech, freedom of expression, or academic 
freedom $(2020,168)$. Despite robust evidence to the contrary, the alt-right claims a position of victimization and oppression for white men that has come about as the result of the small gains to increase equity in universities, small gains which are showcased by universities as evidence of their "progress."

This collection of papers in Atlantis engages with a range of very public moments in which feminist teachers, students, and administrators have faced the type of hostilities described above. The violent ramifications of xenophobic and anti-feminist messaging occurring in educational institutions is not surprising given the ease with which anti-Black racism, anti-feminist positions, and violence continue online and in peoples' everyday lives. Those working in postsecondary education will already have noticed that, predictably, research funding and resources have pivoted to COVID-19-related issues and rightly so. But also very troubling is that the productivity of certain groups of researchers, including women, and anyone with caregiving responsibilities outside of paid work, has declined noticeably (Dolan and Lawless 2020) and that existing inequalities between male and female-identified faculty in doing the service-work associated with academic life reinforces an even more inequitable future for existing and incoming faculty (Guarino and Borden 2017). These studies suggest that a less diverse range of academics and students will be around to receive funds that will shape who is allowed to help solve the problems of COVID-19 and who will be sidelined to the essential work of caregiving in the home, or other forms of caregiving and service within universities. Combined with the hostilities we reference above, the intersections of gendered carework with deep racial inequities in health could also further marginalize many of the people whose presence in universities has only recently become more common. As universities and colleges cope with the impacts of government responses to COVID-19, it is hard not to anticipate plans for more fiscal austerity that may under-fund some of the very educational fields in the liberal arts and sciences where women, Indigenous people, and Black people have made inroads.

To return to the scale of the classroom, hostilities characterized as free speech by proponents and even some university administrations reveal policies that are ill-conceived to deal with the issues that arise from these hostilities. In Living a Feminist Life (2017), Sara Ahmed presents the illogic and disconnections among arguments about Women's and Gender Studies as oversensitive to these problems. These arguments so often flung into the media, sometimes by our own colleagues, unfairly bait students to enter into debates that, for all intents and purposes, reduce peoples' struggles to academic exercises. Those who find themselves the targets of such acts of so-called free speech are frequently under-represented in official responses and are described as censorious and oversensitive when they protest. As Janet Conway argues, the invocation of "free speech" is a deliberate-and easy-attempt to discredit the scholarship, teaching, and expression of marginalized people through what has been a liberal claim (2020). Administrations in Canadian universities have attempted carefully reasoned responses that all too easily ignore the unreasonable conditions in which minoritized students and faculty and their supporters must study and work.

The contributors to this section analyze the barriers, violence, and harassment experienced on a daily basis by feminist university students, faculty, and staff, especially those who are Black, Indigenous, or people of colour, queer, trans, and disabled, which exposes the fallacy of alt-right claims that feminists are oversensitive and unable to tolerate being challenged.

The section opens with an essay by Robyn Bourgeois. "Hostility, Harassment, and Violence: On the Limits of 'Free Speech' for Minority Feminist Scholars" unmasks the opportunistic and hollow character of most free speech defences that occur in the popular media, which tend to defend free speech only when it supports the status quo. Bourgeois begins with the response to her public scholarly analysis of the mass murder of 22 people in rural Nova Scotia on April 1819 , 2020, an analysis which named the murderer's white masculinity as central to understanding this massacre and to disputing an emerging narrative of its 'senselessness.' Predictably, the response was violent and dedicated to silencing her analysis-which is grounded in scholarship and experience-through personal attacks that targeted her as an Indigenous 
woman and mother, threatening physical and sexual violence and calling for her to be fired. Her essay published in this collection guides readers through ten vignettes that explore different facets of the reality that is obscured in right-wing politics and punditry, which is that professors and students who are not white, male, able-bodied, heterosexual, and cisgender are subject to extraordinary scrutiny within and outside of the university, scrutiny that has silencing as its aim. These stories demonstrate the unequal application of so-called free speech principles within the university as well as the popular media, particularly for feminist scholars who are Indigenous, Black, or people of colour.

Elizabeth Brulés article shares a similar interest to Bourgeois's essay, as it examines how marginalised students' activism and speech on campus are regulated and curtailed through student codes of conduct, civility policies, and, most recently, free speech policies in the provinces of Ontario and Alberta. Although a common assumption is that university students enjoy rights of freedom of expression and rights of assembly protected under the Canadian Charter of Rights and Freedoms, universities in Canada have the right to establish their own regulations and policies for speech and conduct, a right outlined in universities' legislative acts and legal statutes. Again, the popular narrative that circulates is about universities obsessed with a political correctness that actively silences groups of students (e.g., white men, conservatives) or positions on social issues (e.g., anti-abortion) in order to maintain a sheltered environment. However, a closer examination of how student codes of conduct and civility policies are used shows that they most often quelch marginalised students' activism and speech and do not protect students from discrimination and harmful speech. Brule proposes that focusing on preventing "harm to one's dignity" over "free speech" is a useful way of balancing the necessity for an expansive vision of expressive freedom on campus with ensuring students are not subject to discrimination and harassment, because such a focus shifts attention from individualised rights to collective responsibility.

Madison McDonald picks up the thread of free speech policies that have been recently mandated by the conservative governments of Ontario and Alberta and at individual universities. "Free Speech Rhetoric and Normalizing Violence" presents an analysis of campus free speech policies that conflate academic freedom and free speech. McDonald argues that heteroactivist, far-right, and alt-right discourses exploit universities' commitment to academic freedom and deploy a framework she calls "bridging rhetoric." Bridging rhetoric refers to the recasting of violent ideologies within more acceptable social norms and discourses; for example, framing a professor's refusal to use a student's requested pronouns as resistance to "compelled speech," rather than as an explicitly transphobic refusal to recognize the student's gender identity. Diverting the attention towards the issue of "compelled speech" stokes anxieties about authoritarianism, normalising the transphobia inherent in the refusal to use someone's requested pronouns. McDonald argues that serious consideration must be given to barring speech that normalises acts of harm, and she analyses the unintended consequences of free speech policies that do not take a position against discrimination and harassment.

Emily Colpitts's article, "Addressing Sexual Violence at Ontario Universities in the Context of Rising AntiFeminist Backlash," is also engaged with questions about university policy-making and what can and cannot be said. In her article, she grapples with the difficulties in naming the root causes of sexual violence within a context shaped by anti-feminist backlash. Colpitts examines how the arguments of anti-feminist groups like Men's Rights Activists and incels shape media discourse about sexual violence on university campuses, creating moral panic about the persecution of white men and the unlimited power of prudish feminist censors at Canadian universities. However, once again the reality is that survivors of sexual violence face significant limits to speech through non-disclosure agreements, and campus sexual violence policies are often written so that systemic oppression (e.g., misogyny, white supremacy) is minimised in favour of individualistic and gender-neutral descriptions of sexual violence. As such, key campus community members-survivors, feminist faculty, and students - are excluded from policy-making, and sexual violence prevention activity is disproportionately directed 
at presenting its messages in a palatable way that will not trigger anti-feminist backlash. Through her analysis, Colpitts explores how anti-feminism limits and shapes how anti-violence work is being done, and argues that concerns about how to deliver these messages to cisgender men have diluted these efforts.

Lindsay Ostridge's "Speaking Freely and Freedom of Speech: Why is Black Feminist Thought Left Out of Ontario University Sexual Violence Policies?" dovetails well with Colpitts's analysis, although Ostridge focuses on a different dimension of sexual violence policies: the theoretical framework that guides the policy-making process. Ostridge offers a detailed analysis of the ways sex and sexual violence continue to be hived off from racialized violence in what would otherwise be a practical application of feminist ideas to making educational institutions freer from violence. In a case study of a standalone campus sexual violence policy, the author examines what administrators hear when mandated to act upon high rates of sexual violence on campus. Specifically, Ostridge argues that decades of Black feminist theorizing and activism that articulate an intersectional approach to challenging violence are ignored in these administrative responses to pressure from feminists themselves. Instead, critical Black feminist concepts like intersectionality are hollowed out to describe individual identities, and administrations are resistant to acknowledging that systems of oppression are interlocked and reinforce one another (Combahee River Collective, 1986). Consequently, administrations continue to criminalize Black people on campus; for example, Ostridge rightly highlights the separation of "women" from "marginalised groups" in the University of Ottawa sexual violence policy, a discursive move that positions white women as reified survivors of sexual violence and "marginalised groups" as other to the campus community.

Heather Latimer's article, "Snapping: Feminist Pedagogy and Navigating the 'New' Right," returns us full-circle to theoretical analysis and reflection on one's experience, this time grounded in affect theory and anecdotal theory (Gallop 2002). Through a critical reflexive analysis of four moments in the classroom, Latimer pushes readers to engage with the affect of "shock" as a response to the contemporary rise of the alt-right and Trumpism as well as the feminist pedagogical challenges of encountering students with passionate attachments to ideas and movements that oppose what they are learning in the Women's and Gender Studies classroom. In her analysis, Latimer argues that reacting with "shock" to evidence of the rise of alt-right ideologies-for example, the election of Donald Trump as President of the United States-is an affective response structured by whiteness, but for students who are Black, Indigenous, and people of colour such events are all too predictable. She considers the consequences of investing time and energies — guided by a feminist pedagogical approach that positions students as responsible for their learning and positions-into supporting privileged students through their exploration and questioning of alt-right ideas and arguments while other students continually crash up against institutional brick walls (Ahmed 2017). Through Sara Ahmed's concept of the "feminist snap," Latimer advocates for a reflexive process that works with the brokenness of the university, not for a naïve optimism but rather for critical engagement that the invitation to snap provides for feminist educators.

The issues and debates broached by contributors to this section are not new. Feminist thinkers have already equipped readers to respond to the alternative right. For generations, the production of ideas, responses, positions, and critical thought about sex, race, sexuality, and power has shaped the field of Women's and Gender Studies, and feminist thought more broadly. The work of Audre Lorde, Sherene Razack, Kimberlé Crenshaw, and so many more equip teachers and students to respond very well. Readers will also be familiar with the work of Himani Bannerji, Linda Carty, Kari Dehli, Susan Heald, and Kate McKenna in Unsettling Relations: The University as a Site of Feminist Struggles, published almost thirty years ago in 1992. This important book also critiqued the permeability of the university to racist and misogynist movements that scaffold and embolden people within higher education to limit the expression of people of colour in particular. In Unsettling Relations, the authors analyzed harassment and discrimination as taking place in classrooms, through labour conditions for faculty, and within the structures of the university, all of which negatively impacted the authors' lives and professional 
security. However, one thing that we observe when reading these still-salient essays in 2020 is that thirty years ago the harassment and discrimination was in many ways contained at the scale of the university and its actors, and at the classroom level in particular. When we reflect on Robyn Bourgeois's essay, we note the significant ways that alt-right groups in the US and Canada can reach directly into the university through the Internet, social media, and email. A recent example of this occurred shortly after North American universities transitioned classes online in response to the coronavirus pandemic. Online classes were interrupted by misogynist, racist, and violent "Zoombombing" attacks and alt-right leaders encouraged students to record their classes to expose their professors online (Redden 2020; Sommer 2020). Thus, what is new about this particular moment is that the public intimacy of online spaces creates exponentially greater opportunities for harassment and violence that redirects the energies of faculty, staff, and students towards disputing specious and bad faith critiques and away from their research and teaching programs.

Among the visible outcomes of people's reactions to the pandemic was an immediate turning inwards of social relationships for essential information. The World Health Organization's exhortation to physically isolate in order to survive COVID-19 risks over-reliance on the consumption of tailored social media messaging for current news. Those already inclined to believe the messages of social conservatives, conspiracy theorists, and white nationalists may be more vulnerable than ever to both mis-information and dis-information during the global pandemic. Given the necessarily delayed reaction of mainstream journalism to covering emerging news under COVID-19 (due to the need for physical distancing), a void has been created in which hatemongering has thrived.

While those who overtly claim membership to white nationalist movements may be fewer in number, those who express degrees of support for these ideas or latently approve of their presence in social media are increasingly emboldened. In online spaces, students, faculty, and staff who are Black, Indigenous, people of colour, feminist, queer, and trans may find themselves subject to verbal and physical hostility. A series of intersecting gendered, racial, and class inequities have been laid bare through different countries' responses to the COVID-19 pandemic. In this special section of Atlantis, we collectively ask: What are the implications of these inequities for feminist research and teaching in the era of free speech debates?

\section{Endnotes}

1. We should note that although the summer of 2020 has seen heightened public attention about racism at Western University, we do not consider Western to be an outlier; indeed, what is remarkable about Western is that students and alumni have been successful in drawing attention to racism on campus in the national media. As we finalize this special section, a group of 34 University of Ottawa professors have signed a public letter defending another professor who used the nword in class and was suspended. The signatories claim that her suspension is a threat to academic freedom and critical thinking, while Black and Indigenous students are organizing to challenge this claim and draw attention to the racism they face at uOttawa (Glowacki 2020). 


\section{References}

Ahmed, Sara. 2017. Living a Feminist Life. Durham: Duke University Press.

. 2014. "White Men.” Feminist Killjoys (blog), https://feministkilljoys.com/2014/11/04/white-men/.

. 2012. On Being Included: Racism and Diversity in Institutional Life. Durham: Duke University Press.

Boisvert, Nick. 2020. "Homicide at Toronto Massage Parlour Was an Act of Incel Terrorism, Police Say." CBC News, May 19, 2020. https://www.cbc.ca/news/ canada/toronto/incel-terrorism-massage-parlour1.5575689

CBC News. 2020a. "Alek Minassian admits in court document to planning, carrying out Toronto van attack," March 5, 2020. https://www.cbc.ca/news/ canada/toronto/minassian-admits-planning-torontovan-attack-1.5486848

CBC News. 2020b. "Immigration advocates demand permanent status for asylum seekers working in Quebec's long-term care homes," June 6, 2020. https:// www.cbc.ca/news/canada/montreal/asylum-seekersimmigration-covid-19-front-lines-chsld-quebec1.5601868

Combahee River Collective. 1986. The Combahee River Collective Statement : Black Feminist Organizing in the Seventies and Eighties. Albany, NY: Kitchen Table: Women of Color Press.

Conway, Janet. 2020. "Notes on Free Speech Fights, Anti-feminism and the Rising Right." Seminar presentation at St. Francis Xavier University, Antigonish, Nova Scotia, March 13, 2020.

Crenshaw, Kimberle. 1991. "Mapping the Margins: Intersectionality, Identity Politics, and Violence Against Women of Color." Stanford Law Review 43, no. 6: 1241-1299.
DiAngelo, Robin. 2018. White Fragility: Why It's So Hard for White People to Talk About Racism. Boston: Beacon Press.

Dolan, Kathleen and Jennifer L. Lawless. 2020. "It Takes a Submission: Gendered Patterns in the Pages of AJPS." American Journal of Political Science (blog), https://ajps.org/2020/04/20/it-takes-a-submissiongendered-patterns-in-the-pages-of-ajps/.

Gillis, Wendy. "What Happened the Night Regis Korchinski-Paquet Died, According to Ontario's Police Watchdog." The Toronto Star, August 28, 2020. https://www.thestar.com/news/gta/2020/08/26/whathappened-the-night-regis-korchinski-paquet-diedaccording-to-ontarios-police-watchdog.html

Glowacki, Laura. 2020. "Students Decry Letter Defending N-word Use at the University of Ottawa." CBC News, October 20, 2020. https:/www.cbc.ca/ news/canada/ottawa/university-of-ottawa-professorracism- 1.5768730

Guarino, Cassandra M., and Victor M.H. Borden. 2017. "Faculty Service Loads and gender: Are Women Taking Care of the Academic Family?" Research in Higher Education 58, no.6: 672-694.

Hodge, Edwin, and Helga Hallgrimsdottir. "Networks of hate: the alt-right, "troll culture", and the cultural geography of social movement spaces online." Journal of Borderlands Studies 35.4 (2020): 563-580.

Henry, Frances, Enakshi Dua, Carl E. James, Audrey Kobayashi, Peter Li, Howard Ramos, and Malinda S. Smith. 2017. The Equity Myth: Racialization and Indigeneity at Canadian Universities. Vancouver: UBC Press.

Humphreys, Adrian. 2020. "With COVID-19 Clampdown, Number of Asylum Seekers at CanadaU.S. Border Slows to a Trickle." The National Post, April 6, 2020. https://nationalpost.com/news/withcovid-19-clampdown-number-of-asylum-seekers-atcanada-u-s-border-slows-to-a-trickle 
Ibrahim, Hadeel. 2020. "Killing of Indigenous Woman Raises Questions About Who Should Be Doing Wellness Checks.” CBC News, Jun 6, 2020 https://www.cbc.ca/news/canada/new-brunswick/ chantel-moore-indigenous-woman-shot-by-policeedmundston- 1.5601097

Joseph, J. Ameil, Julia Janes, Harjeet Badwall and Shana Almeida. "Preserving White Comfort and Safety: The Politics of Race Erasure in Academe." Social Identities 26, 2 (2020): 166-185.

Lorde, Audre. 2012. Sister outsider: Essays and speeches. Berkeley, CA: Crossing Press.

Martis, Eternity. 2020. They Said This Would Be Fun: Race, Campus Life, and Growing Up. Toronto: Penguin Random House Canada.

Pickard, Arron. "Marcus Drive 'Incel' Attacker Told Police He Was 'Out to Murder a Little White Girl'." Sudbury.com, January 13, 2020. https:// www.sudbury.com/local-news/marcus-drive-incelattacker-told-police-he-was-out-to-murder-a-littlewhite-girl-2018238

Porter, Jody. 2017. "First Nations Woman Dies After Being Hit by Trailer Hitch Thrown From Passing Car in Thunder Bay, Ont." CBC News, July 4, 2017. https://www.cbc.ca/news/canada/thunder-bay/trailerhitch-death-1.4189426

Razack, Sherene. 1998. Looking White People in the Eye: Gender, Race, and Culture in Courtrooms and Classrooms. Toronto: University of Toronto Press.

Redden, Elizabeth. “'Zoombombing' Attacks Disrupt Classes." Inside Higher Ed, March 26, 2020. Accessed October 16, 2020. https:/www.insidehighered.com/ news/2020/03/26/zoombombers-disrupt-onlineclasses-racist-pornographic-content

Rodriguez, Sofia. 2020. "Black Alumni Call for Action to Combat Philippe Rushton's Racist Legacy at Western University." CBC News, July 14, 2020. https://www.cbc.ca/news/canada/london/black-atwestern-alumni-philippe-rushton-1.5647765
Sommer, Will. "Right-Wing Tricksters Want to Discredit Academia by Recording Zoom Classes." The Daily Beast, March 25, 2020. Accessed October 16, 2020. https://www.thedailybeast.com/right-wingtricksters-want-to-discredit-academia-by-recordingzoom-classes-during-coronavirus-outbreak 